\title{
Large genomic deletions inactivate the BRCA2 gene in breast cancer families
}

\author{
S Agata, M Dalla Palma, M Callegaro, M C Scaini, C Menin, C Ghiotto, O Nicoletto, G Zavagno, \\ L Chieco-Bianchi, E D’Andrea, M Montagna
}

J Med Genet 2005;42:e64 (http://www.jmedgenet.com/cgi/content/full/42/10/e64). doi: 10.1136/jmg.2005.032789

\begin{abstract}
Background: BRCA1 and BRCA2 are the two major genes responsible for the breast and ovarian cancers that cluster in families with a genetically determined predisposition. However, regardless of the mutation detection method employed, the percentage of families without identifiable alterations of these genes exceeds $50 \%$, even when applying stringent criteria for family selection. A small but significant increase in mutation detection rate has resulted from the discovery of large genomic alterations in BRCA1. A few studies have addressed the question of whether BRCA2 might be inactivated by the same kinds of alteration, but most were either done on a relatively small number of samples or employed cumbersome mutation detection methods of variable sensitivity.

Objective: To analyse 121 highly selected families using the recently available $B R C A 2$ multiplex ligation dependent probe amplification (MLPA) technique.

Results: Three different large genomic deletions were identified and confirmed by analysis of the mutant transcript and genomic characterisation of the breakpoints.

Conclusions: Contrary to initial suggestions, the presence of $B R C A 2$ genomic rearrangements is worth investigating in high risk breast or ovarian cancer families.
\end{abstract}

dentification of BRCAl (OMIM No 113705) and BRCA2 (OMIM No 600185) pathogenic mutations is a major concern for geneticists counselling families at high risk for breast and ovarian cancer. ${ }^{1}$ Point mutations, which recur only in distinct ethnically closed populations, are spread throughout the whole coding sequence of both genes (Breast cancer Information Core database http://www.nhgri.nih.gov/ Intramural_research/Lab_transfer/Bic/) and account for only $10-50 \%$ of the families depending on the selectivity of inclusion criteria. This has raised several hypotheses as to the acting genetic determinants in the remaining families. Among these, the presence of other dominant genes has been suggested by more than one study ${ }^{2-4}$; this possibility, however, failed to be replicated. ${ }^{56}$ Low penetrant alleles have also been considered as possible causes of increased breast cancer risk in the context of polygenic models. For instance, the recently investigated 1100delC mutation in the CHEK2 gene has been shown to be associated with a twofold increase in breast cancer risk. ${ }^{7}$ However, this allele has a low population frequency and is nearly absent in Mediterranean countries such as Italy.

An additional explanation for families without detectable $B R C A 1$ or $B R C A 2$ point mutations comes from the identification of alterations that escape most common point mutation detection approaches. In the BRCAl gene, such mutations are more frequently represented by large deletions and duplications that disrupt one or more exon, causing the synthesis of aberrant proteins. Over the past eight years several of these rearrangements have been identified and have been shown to account for a population specific proportion of the BRCAl mutational spectrum. ${ }^{9-15}$ Conversely, whether the same kind of mutations could be responsible for $B R C A 2$ gene inactivation is not yet clear.

After the cloning of the gene in 1995, BRCA2 genomic rearrangements were sporadically identified in the screening for point mutations. ${ }^{16} 17$ This finding, together with the increasingly frequent identification of genomic rearrangements in BRCA1, led to the assumption that BRCA2 inactivation in hereditary breast cancer patients could be achieved by a similar mechanism, thus prompting studies focused on identification of BRCA2 genomic rearrangements. Surprisingly, only two genomic rearrangements were identified in two of six different studies that analysed hereditary breast cancer patients or primary breast tumours in five diverse European populations, ${ }^{18-23}$ thus creating doubt as to the value of screening the $B R C A 2$ gene for such alterations. On the other hand, a very recent study has reported the identification of three different large genomic alterations in the BRCA2 gene in independent French male breast cancer families. $^{24}$

\section{METHODS}

The 121 probands analysed in this study belonged to different high risk classes. In particular, according to published operational criteria, ${ }^{25} 87$ were classified as hereditary breast/ ovarian cancer (HBC/HBOC) and 34 belonged to the suspected hereditary breast/ovarian cancer (SHBC/SHBOC) class. Briefly, the HBC/HBOC class involved (1) no less than three tumour cases (with at least one ovarian cancer in HBOC) in a minimum of two generations on the same parental branch; (2) cases occurring among first degree relatives (with the exception of disease transmitting males); (3) at least one case diagnosed under 40 years of age or with bilateral disease. The family was defined as SHBC/SHBOC when either one of the last two criteria was not satisfied.

The study was carried out in accordance with the principles embodied in the declaration of Helsinki and was approved by both the ethical and technical-scientific committees of the Oncology Centre of the Veneto Region in Padua, acting as our institutional review board.

Blood samples were obtained from each affected proband after receiving their informed consent. Epstein-Barr virus (EBV) immortalised lymphoblastoid cell lines were established from peripheral blood lymphocytes. DNA was extracted by means of standard phenol-chloroform techniques, and RNA

Abbreviations: DHPLC, denaturing high performance liquid chromatography; $\mathrm{HBC} / \mathrm{HBOC}$, hereditary breast/ovarian cancer; MLPA, multiplex ligation dependent probe amplification; SHBC/SHBOC, suspected hereditary breast/ovarian cancer 


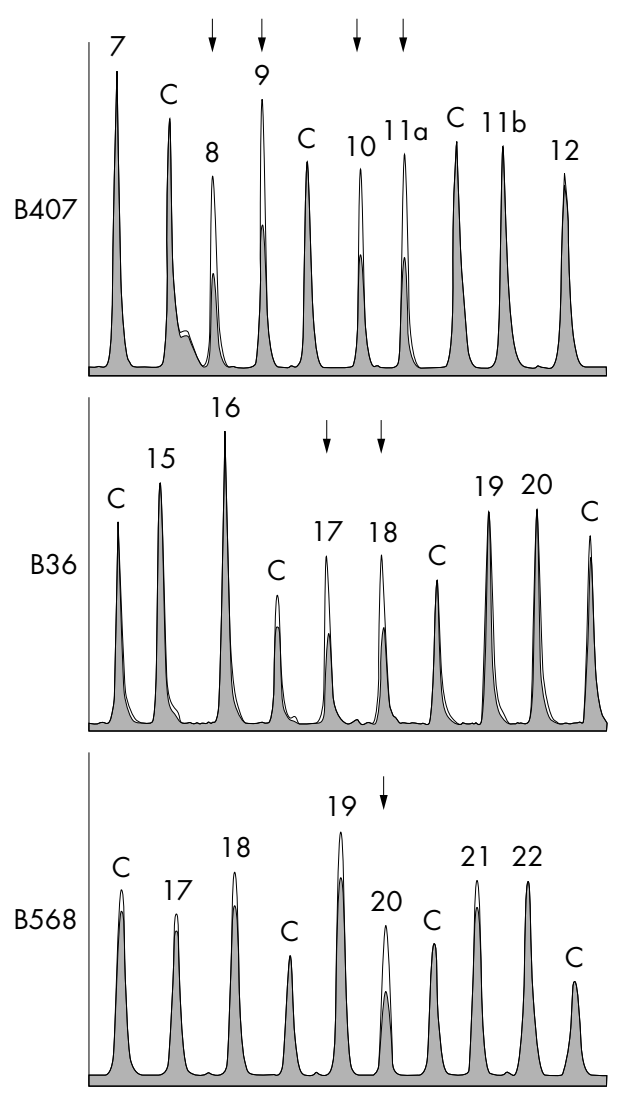

Figure 1 BRCA2 multiplex ligation dependent probe amplification (MLPA) results of three breast cancer patients. The patients' profiles (grey) are overlaid on a normal sample. Numbers refer to the BRCA2 exons recognised by each MLPA probe. Arrows mark the deleted BRCA2 exons; $C$ indicates the control peaks resulting from the amplification of probes located on different chromosomes.

was isolated using RNAzol reagent (Tel-Test, Friendwood, Texas, USA).

The multiplex ligation dependent probe amplification (MLPA) procedure was carried out according to the manufacturer's instructions (MRC Holland, Amsterdam, Netherlands) on a PTC 200 thermal cycler (MJ Research, Waltham, Massachusetts, USA) using FAM labelled primers. Variations in peak height were evaluated by comparing each sample with a normal control and by cumulative comparisons of three to five samples from the same experiment.

Long range polymerase chain reaction (PCR) was done with the Expand Long Template PCR system (Roche Indianapolis, Indiana, USA) according to the suggestions provided by the manufacturer. Reverse transcriptase PCR (RT-PCR) analysis of the BRCA2 transcripts was carried out using Superscript ${ }^{\mathrm{TM}}$ RT $\mathrm{RnaseH}^{-}$reverse transcriptase (Invitrogen, Carlsbad, California, USA). Primer couples employed to amplify the breakpoint region from cDNA or genomic DNA are available on request.

All sequence reactions were done with the DNA sequencing kit (Applied Biosystems, Foster City, California, USA) and subjected to capillary electrophoresis with the ABI Prism-310 genetic analyser (Applied Biosystems).

The sequences around the breakpoints were compared with the following recombination associated motifs: vertebrate topoisomerase II consensus cleavage site (RNYNNCNNGYN GKTNYNY); heptamer recombination signal (CACAGTG); nonamer recombination signal (ACAAAAACC); immunoglobulin heavy chain class switch repeats (GAGCT,GGGCT, GGGGT,TGGGG,TGAGC); translin target sites (ATGCAG,
GCCCWSSW); Chi element (GCTGGTGG); mariner transposon-like element (GAAAATGAAGCTATTTACCCAGGA).

\section{RESULTS AND DISCUSSION}

Among all breast and breast/ovarian cancer families ascertained through our centre, 121 fulfilled highly selective criteria and had no point mutations identified by screening of the entire BRCAI and BRCA2 gene coding sequences by denaturing high performance liquid chromatography (DHPLC) analysis. A negative result was obtained by the MLPA analysis of BRCAl major genomic rearrangements in all of them. To investigate the role of genomic rearrangements in the inactivation of the BRCA2 gene, we employed the recently available $B R C A 2$ MLPA methodology which analyses 23 of the 27 exons of the gene. The remaining exons $(5,6,23$, and 26$)$ are located in close proximity to genomic regions covered by the MLPA probes, and therefore were not supposed to be selectively involved in genomic alterations. Of all abnormal profiles obtained after the first screening, three were consistently detected after multiple analyses (fig 1). Based on the decreased signals from the probes corresponding to one or more exon, three different deletions could be suspected. The three affected probands belonged to the HBC and HBOC family classes which show the highest BRCA2 mutation frequency in our series of samples. ${ }^{26}$ Families of patients B407 and B568 contained five and six breast cancer cases, respectively, including two bilateral tumours and a male breast cancer patient in the latter, whereas proband B36 belonged to a breast/ovarian family with two bilateral breast cancer cases.

To confirm these preliminary data, we carried out RT-PCR experiments using primer pairs located in the exons surrounding the deletions (fig 2A). While the expected deletion of exon 20 was confirmed by sequencing of the additional RT-PCR product in patient B568, in the other two cases additional exons were involved in the generation of the aberrant transcripts. In particular, besides exons 17 and 18 , the entire sequence of exon 19 was missing from the major aberrant transcript of patient B36. Similarly, part of exon 7, which was associated with a normal signal in the MLPA analysis, was deleted from patient B407 mutant transcript and led to the joining of the first 79 nucleotides of exon 7 to the last 301 nucleotides of exon 11. In all three cases, the absence of one or more exon caused a frameshift leading to premature stop codons (table 1).

Next we proceeded towards the characterisation of the rearrangements at the genomic level to investigate the mechanisms underlying the alterations and to gain an understanding of the apparent discrepancies between the MLPA and RT-PCR results in patients B36 and B407. As the density of Alu repeats located in the BRCA2 locus is considerably lower than that observed in BRCAl, ${ }^{27}$ it is sometimes feasible to hypothesise the location of the potentially recombining Alu sequences, based on the fact that deletions resulting from Alu mediated homologous recombination are usually caused by repeats with the same orientation (that is, direct repeats). ${ }^{28}$ This was the case in patient B568, in whom only one of the three Alu sequences located in intron 20 (Alu 61328-61626) had the same orientation as the Alu present in intron 19 (nucleotides 56379-56660). Long range PCR amplification experiments using primers located upstream of exon 19 and downstream of exon 21 finally resulted in the amplification of a $1.6 \mathrm{~kb}$ fragment selectively present in sample B568 (fig 2B). Complete sequencing of this fragment confirmed the involvement of the above mentioned Alu sequences, which displayed an overall $87 \%$ homology and shared a 34 base pair (bp) identical sequence in the region including the breakpoint. Multiple long range PCR amplifications, aimed at 
A
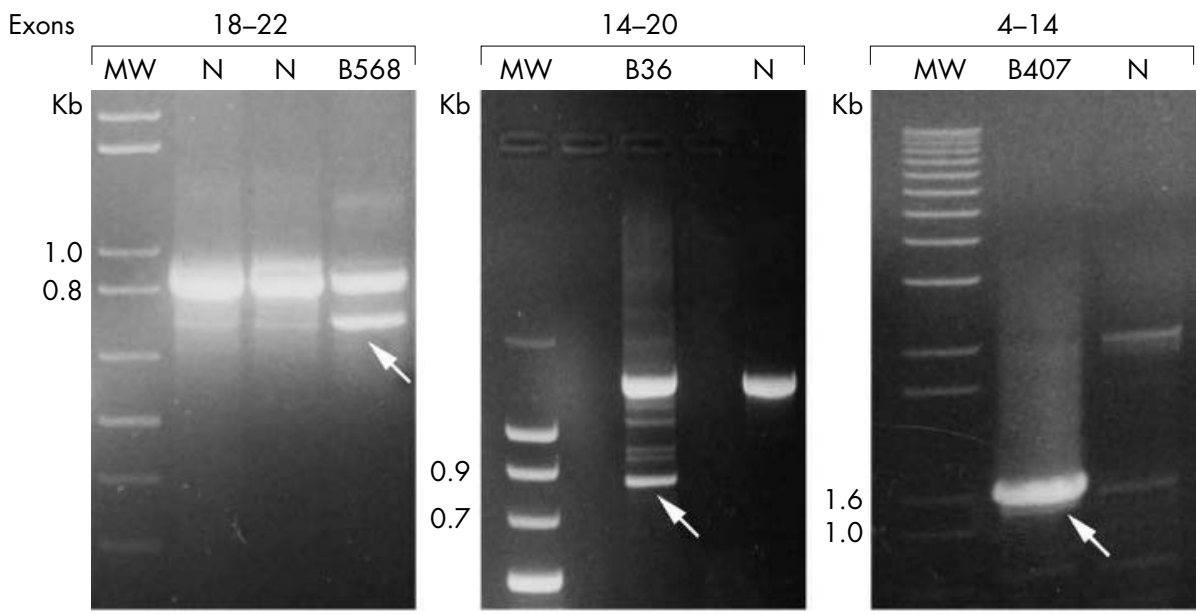

B
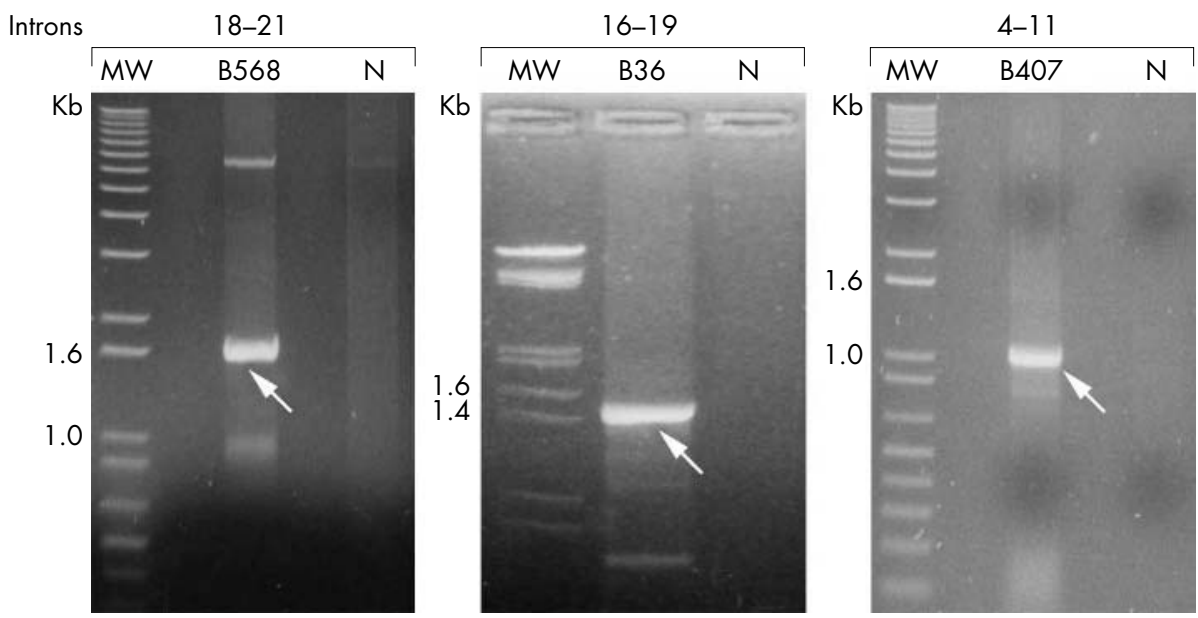

Figure 2 Characterisation of BRCA2 mutant transcripts and breakpoint sequences. (A) Reverse transcriptase polymerase chain reaction (RT-PCR) products of probands B568, B36, B407, and normal controls (N); arrows indicate the aberrant transcripts. Exons containing the primers used for PCR are shown in the top figure. Owing to the large size, the wild-type sequences of patient B407 and normal controls were not amplified. (B) DNA PCR of the breakpoint containing regions in patients B568, B36, B407, and normal controls (N). Arrows indicate the rearranged bands present only in the patients. Owing to the large size, the wild-type sequences were amplified only in patient B568 and the corresponding normal control. Introns containing the primers used for PCR are shown in the top figure.

narrowing the breakpoint containing regions, were also carried out for the other two patients and finally led to PCR products of 1.0 and $1.4 \mathrm{~kb}$ which could then be easily sequenced (fig 2B).

Although several Alu repeats were identified in the mutant allele of patient B36, apparently none of them was directly involved in the rearrangement as the breakpoint occurred across a five nucleotide repeat located at both ends of the joined sequences, 128 and 334 nucleotides distant from the nearest Alu. Exon 19, previously shown to be absent from the mutant transcript, was not involved in the deletion, thus suggesting that the exon 19 deleted transcript was probably the result of the preferential combination of specific donor and acceptor splicing sites which, in the absence of the physiological splicing sequences caused by exon deletion or duplication, favours the joining of non-adjacent exons. Similar observations were previously made in the analysis of BRCAl rearrangement associated mutant transcripts. ${ }^{15}$ Similarly, no Alu sequences appeared to be involved in the rearrangement of patient B407. In this case, the breakpoint coincided with that observed at the cDNA level and no repeated sequences were located at the ends of the

Table 1 Characteristics of BRCA2 genomic rearrangements in three patients belonging to breast or ovarian cancer families

\begin{tabular}{llll}
\hline Patient & MLPA (exons) & Mutant transcripts (NM_000059)* & Mutation designation (AY436640) \\
\hline B36 & $17-18$ & c.8034_8715 ter 2635 (del. ex. 17-19) & g.45138_55975del10838 (del. ex. 17-18) \\
B407 & $8-11$ a & c.824_6768 ter206 (del. ex. 7-11) & g. 12323_26644del14322 (del. ex. 7-11) \\
B568 & 20 & c.8716_8860 ter2842 (del ex. 20) & g.56447_61399del4953 (del. ex. 20) \\
\hline
\end{tabular}

*Numbers between brackets correspond to GenBank sequence accession numbers.

†Exons partially deleted.

MLPA, multiplex ligation dependent probe amplification. 
recombining sequences. The apparently normal MLPA signal corresponding to exon 7 is probably explained by the location of exon 7 specific probes that cover only a 20 to 30 nucleotide region surrounding the ligation site at nucleotide 765-766 which, conversely, is located 59 positions upstream of the first deleted nucleotide. The coordinates of each of the three patients' breakpoints, as well as the rearrangement associated transcript characteristics, are shown in table 1.

Therefore, while the rearrangement of proband B568 was shown to be clearly the result of highly homologous Alu sequences, deletion breakpoints occurred at a minimum of 128 nucleotides distant from the closest Alu repeat in patients B36 and B407, suggesting a different mechanism than Alu mediated unequal homologous recombination. Non-homologous recombination was also apparently involved in at least one of the few previously described $B R C A 2$ rearrangements with characterised breakpoints, ${ }^{17}$ thus envisaging a scenario different from that of the BRCAl gene, where the vast majority of the rearrangements are mediated by Alu sequences.

Non-homologous recombination occurs between sites that show minimal sequence homology and is sometimes associated with small insertions. Several rather heterogeneous sequence dependent mechanisms have been suggested as activators of this process. To gain insight into the mutagenic mechanisms underlying the rearrangements observed in patients $\mathrm{B} 36$ and $\mathrm{B} 407$, the 15 nucleotides flanking the breakpoint junctions in the two patients were screened for the presence of various recombination associated motifs (see Methods for a complete list), among which the translin target sites and the immunoglobulin switch repeats were recently found to be significantly overrepresented in a large number of translocation and deletion breakpoints. ${ }^{29}$ None of these sequence motifs, however, was identified at the breakpoint regions. The breakpoint sequences were also screened for direct, inverted, and mirror repeats, which have recently been associated with the formation of non-conventional DNA conformations that might predispose to gene rearrangements. ${ }^{30}$ Several very short repeats of this type were identified in the recombining sequences of both patients; nonetheless, the unambiguous demonstration of their causal role remains elusive.

Whatever mechanisms are responsible for the observed genomic alterations, we suggest that an estimation of the expected frequency of BRCA2 genomic rearrangements based simply on the density of Alu repeats is likely to be misleading and ought to take account of alternative and as yet uncharacterised mechanisms. It is noteworthy that the occurrence of non-Alu rearrangements possibly with intraexon breakpoints has important practical consequences for the technical approach employed. Until the underlying mechanisms are discovered and used for designing new ad hoc screening procedures, a comprehensive rearrangement detection screen should carefully consider every part of all the exons of the gene.

In this study we analysed 121 probands in which no $B R C A 1$ or BRCA2 mutations were detected by DHPLC and BRCA1MLPA screening. All patients belonged to independent breast and breast/ovarian cancer families classified in high risk categories. Considering the 24 families belonging to the same risk classes and excluded from BRCA2 MLPA screening because of a BRCA2 point mutation, genomic rearrangements of the BRCA2 gene accounted for $11 \%(3 / 27)$ of the BRCA2 mutational spectrum (95\% confidence interval, $3 \%$ to $26 \%$ ). These data are in agreement with those recently reported on French breast cancer families estimating the contribution of BRCA2 rearrangements to $10 \%$ of all BRCA2 gene defects. ${ }^{24}$ Nonetheless, considering the well documented worldwide description of founder derived recurrent mutations in BRCA2 and BRCAl, including genomic rearrangements in the latter, we believe that screening for major genomic alterations of the $B R C A 2$ gene should be carried out in all countries in families without detectable point mutations, at least until more precise prevalence figures are available for such kinds of alterations.

\section{ELECTRONIC DATABASE INFORMATION}

OMIM No 113705 (BRCA1); OMIM No 600185 (BRCA2); GenBank: AY436640 (genomic), NM_000059 (mRNA); http://www.nhgri.nih.gov/Intramural_research/Lab_transfer/ Bic/ (BIC database)

\section{ACKNOWLEDGEMENTS}

We thank D Zullato and M Quaggio for their expert technical assistance, P Gallo and A Azzalini for artwork, and C Case for help in preparing the manuscript. The study was supported by grants from the Ministero della Ricerca Scientifica e Tecnologica (FIRB '01; PRIN '03), Associazione Italiana per la Ricerca sul Cancro (AIRC), Lega Italiana per la lotta contro i Tumori (LILT) and Fondazione Cassa di Risparmio di Padova e Rovigo.

\section{Authors' affiliations \\ S Agata, M Dalla Palma, M Callegaro, M C Scaini, L Chieco-Bianchi, E D'Andrea, Department of Oncology and Surgical Sciences, Oncology Section, Padua, Italy \\ C Menin, M Montagna, IST-Genova c/o Azienda Ospedaliera, Padua C Ghiotto, O Nicoletto, Oncologia Medica, Azienda Ospedaliera, Padua \\ G Zavagno, Clinica Chirurgica II, Azienda Ospedaliera, Padua \\ Competing interests: none declared}

Correspondence to: Dr Marco Montagna, Department of Oncology and Surgical Sciences, Oncology Section, via Gattamelata 64, I-35128 Padua, Italy; montagna@unipd.it

Received 14 March 2005

Revised version received 17 May 2005

Accepted for publication 20 May 2005

\section{REFERENCES}

1 Wooster R, Weber BL. Breast and ovarian cancer. N Engl J Med 2003:348:2339-47.

2 Seitz S, Rohde K, Bender E, Nothnagel A, Pidde H, Ullrich OM, El-Zehairy A, Haensch W, Jandrig B, Kolble K, Schlag PM, Scherneck S. Deletion mapping and linkage analysis provide strong indication for the involvement of the human chromosome region 8p12-p22 in breast carcinogenesis. Br J Cancer 1997;76:983-91.

3 Kainu T, Juo SH, Desper R, Schaffer AA, Gillanders E, Rozenblum E, FreasLutz D, Weaver D, Stephan D, Bailey-Wilson J, Kallioniemi OP, Tirkkonen M, Syrjakoski K, Kuukasjarvi T, Koivisto P, Karhu R, Holli K, Arason A, Johannesdottir $G$, Bergthorsson JT, Johannsdottir H, Egilsson V Barkardottir RB, Johannsson O, Haraldsson K, Sandberg T, Holmberg E, Gronberg H, Olsson H, Borg A, Vehmanen P, Eerola H, Heikkila P, Pyrhonen S, Nevanlinna H. Somatic deletions in hereditary breast cancers implicate 13q21 as a putative novel breast cancer susceptibility locus. Proc Natl Acad Sci USA 2000;97:9603-8.

4 Sobol H, Birnbaum D, Eisinger F. Evidence for a third breast-cancer susceptibility gene. Lancet 1994;344:1151-2.

5 Rahman N, Teare MD, Seal S, Renard H, Mangion J, Cour C, Thompson D, Shugart $Y$, Eccles D, Devilee P, Meijers H, Nathanson KL, Neuhausen SL, Weber B, Chang-Claude J, Easton DF, Goldgar D, Stratton MR. Absence of evidence for a familial breast cancer susceptibility gene at chromosome 8p12p22. Oncogene 2000;19:4170-3.

6 Thompson D, Szabo Cl, Mangion J, Oldenburg RA, Odefrey F, Seal S, Barfoot R, Kroeze-Jansema K, Teare D, Rahman N, Renard H, Mann G, Hopper JL, Buys SS, Andrulis IL, Senie R, Daly MB, West D, Ostrander EA, Offit K, Peretz T, Osorio A, Benitez J, Nathanson KL, Sinilnikova OM, Olah E, Bignon YJ, Ruiz P, Badzioch MD, Vasen HF, Futreal AP, Phelan CM, Narod SA, Lynch HT, Ponder BA, Eeles RA, Meijers-Heijboer H, StoppaLyonnet D, Couch FJ, Eccles DM, Evans DG, Chang-Claude J, Lenoir G, Weber BL, Devilee P, Easton DF, Goldgar DE, Stratton MR. Evaluation of linkage of breast cancer to the putative BRCA3 locus on chromosome 13q21 in 128 multiple case families from the Breast Cancer Linkage Consortium. Proc Natl Acad Sci USA 2002;99:827-31.

7 CHEK2 Breast Cancer Case-Control Consortium. CHEK2*1100delC and susceptibility to breast cancer: a collaborative analysis involving 10,860 breast cancer cases and 9,065 controls from 10 studies, Am J Hum Genet 2004; 74: 1175-82. 
8 Caligo MA, Agata S, Aceto G, Crucianelli R, Manoukian S, Peissel B Scaini MC, Sensi E, Veschi S, Cama A, Radice P, Viel A, D'Andrea E, Montagna M. The CHEK2 c. 1100 delC mutation plays an irrelevant role in breast cancer predisposition in Italy. Hum Mutat 2004;24:100-1.

9 Unger MA Nathanson KL, Calzone K, Antin-Ozerkis D, Shih HA, Martin AM, Lenoir GM, Mazoyer S, Weber BL. Screening for genomic rearrangements in families with breast and ovarian cancer identifies BRCA1 mutations previously missed by conformation-sensitive gel electrophoresis or sequencing. Am J Hum Genet 2000;67:841-50

10 Casilli F, Di Rocco ZC, Gad S, Tournier I, Stoppa-Lyonnet D, Frebourg T, Tosi M. Rapid detection of novel BRCA1 rearrangements in high-risk breastovarian cancer families using multiplex PCR of short fluorescent fragments. Hum Mutat 2002;20:218-26.

11 Puget N, Stoppa-Lyonnet D, Sinilnikova OM, Pages S, Lynch HT, Lenoir GM, Mazoyer S. Screening for germ-line rearrangements and regulatory mutations in BRCAl led to the identification of four new deletions. Cancer Res 1999;59:455-61.

12 Hogervorst FB, Nederlof PM, Gille JJ, McElgunn CJ, Grippeling M, Pruntel R, Regnerus R, van Welsem T, van Spaendonk R, Menko FH, Kluijt I, Dommering C, Verhoef S, Schouten JP, van't Veer $\sqcup$, Pals G. Large genomic deletions and duplications in the BRCA1 gene identified by a novel quantitative method. Cancer Res 2003;63:1449-53.

13 Gad S, Caux-Moncoutier V, Pages-Berhouet S, Gauthier-Villars M, Coupier I, Pujol P, Frenay M, Gilbert B, Maugard C, Bignon YJ, Chevrier A, Rossi A, Fricker JP, Nguyen TD, Demange L, Aurias A, Bensimon A, Stoppa-Lyonnet D. Significant contribution of large BRCA1 gene rearrangements in 120 French breast and ovarian cancer families. Oncogene 2002;21:6841-7.

14 Hartmann C, John AL, Klaes R, Hofmann W, Bielen R, Koehler R, Janssen B, Bartram CR, Arnold N, Zschocke J. Large BRCA1 gene deletions are found in $3 \%$ of German high-risk breast cancer families. Hum Mutat 2004;24:534.

15 Montagna M, Dalla Palma M, Menin C, Agata S, De Nicolo A, ChiecoBianchi L, D'Andrea E. Genomic rearrangements account for more than onethird of the BRCA1 mutations in northern Italian breast/ovarian cancer families. Hum Mol Genet 2003;12:1055-61.

16 Miki Y, Katagiri T, Kasumi F, Yoshimoto T, Nakamura Y. Mutation analysis in the BRCA2 gene in primary breast cancers. Nat Genet 1996;13:245-7.

17 Nordling M, Karlsson P, Wahlstrom J, Engwall Y, Wallgren A, Martinsson T. A large deletion disrupts the exon 3 transcription activation domain of the BRCA2 gene in a breast/ovarian cancer family. Cancer Res 1998;58:1372-5.

18 Gad S, Klinger M, Caux-Moncoutier V, Pages-Berhouet S, Gauthier-Villars M Coupier I, Bensimon A, Aurias A, Stoppa-Lyonnet D. Bar code screening on combed DNA for large rearrangements of the BRCA1 and BRCA2 genes in French breast cancer families. J Med Genet 2002;39:817-21
19 Lahti-Domenici J, Rapakko K, Paakkonen K, Allinen M, Nevanlinna H, Kujala M, Huusko P, Winqvist R. Exclusion of large deletions and other rearrangements in BRCA1 and BRCA2 in Finnish breast and ovarian cancer families. Cancer Genet Cytogenet 2001;129:120-3.

20 Chin SF, Wang Q, Puisieux A, Caldas C. Absence of rearrangements in the BRCA2 gene in human cancers. Br J Cancer 2001;84:193-5.

21 Peelen T, van Vliet M, Bosch A, Bignell G, Vasen HF, Klijn JG, MeijersHeijboer H, Stratton M, van Ommen GJ, Cornelisse CJ, Devilee P. Screening for BRCA2 mutations in 81 Dutch breast-ovarian cancer families. Br J Cancer 2000;82:151-6.

22 Wang T, Lerer I, Gueta Z, Sagi M, Kadouri L, Peretz T, Abeliovich D. A deletion/insertion mutation in the BRCA2 gene in a breast cancer family: a possible role of the Alu-polyA tail in the evolution of the deletion. Genes Chromosomes Cancer 2001;31:91-5.

23 Bunyan DJ, Eccles DM, Sillibourne J, Wilkins E, Thomas NS, Shea-Simonds J, Duncan PJ, Curtis CE, Robinson DO, Harvey JF, Cross NC. Dosage analysis of cancer predisposition genes by multiplex ligation-dependent probe amplification. Br J Cancer 2004;91:1155-9.

24 Tournier I, Paillerets BB, Sobol H, Stoppa-Lyonnet D, Lidereau R, Barrois M Mazoyer S, Coulet F, Hardouin A, Chompret A, Lortholary A, Chappuis $P$, Bourdon V, Bonadona V, Maugard C, Gilbert B, Nogues C, Frebourg T, Tosi M. Significant contribution of germline BRCA2 rearrangements in male breast cancer families. Cancer Res 2004;64:8143-7.

25 Federico M, Maiorana A, Mangone L, Turchetti D, Canossi B, Cortesi L, Romagnoli R, Silingardi V. Identification of families with hereditary breast and ovarian cancer for clinical and mammographic surveillance: the Modena Study Group proposal. Breast Cancer Res Treat 1999;55:213-21.

26 Marroni F, Aretini P, D'Andrea E, Caligo MA, Cortesi L, Viel A, Ricevuto E, Montagna M, Cipollini G, Ferrari S, Santarosa M, Bisegna R, BaileyWilson JE, Bevilacqua G, Parmigiani G, Presciuttini S. Evaluation of widely used models for predicting BRCA1 and BRCA2 mutations. J Med Genet 2004;41:278-85

27 Welcsh PL, King MC. BRCA1 and BRCA2 and the genetics of breast and ovarian cancer. Hum Mol Genet 2001;10:705-13.

28 Lupski JR. Genomic disorders: structural features of the genome can lead to DNA rearrangements and human disease traits. Trends Genet 1998; 14:417-22

29 Abeysinghe SS, Chuzhanova N, Krawczak M, Ball EV, Cooper DN. Translocation and gross deletion breakpoints in human inherited disease and cancer I: Nucleotide composition and recombination-associated motifs. Hum Mutat 2003;22:229-44

30 Bacolla A, Wells RD. Non-B DNA conformations, genomic rearrangements, and human disease. J Biol Chem 2004;279:4741 1-14. 